\title{
The politics within institutions for regulating public spending: conditional compliance within multi-year budgets
}

\section{Bernard Steunenberg $^{1}$}

Accepted: 30 October 2020 / Published online: 13 November 2020

(C) The Author(s) 2020

\begin{abstract}
Multi-year budget frameworks are often considered as instruments for controlling spending, including in the context of the European Union. This paper shows that the effects of multi-year budgeting depends on several conditions, some of which, may lead to more rather than less spending. The analysis is based on a model of a finance minister's decision to enforce a previously accepted budget ceiling in subsequent negotiations with a spending minister. The analysis takes account of uncertainty about preferences in these negotiations, positive transaction costs to the finance minister, and the possibility of political mediation through the prime minister. The findings of this paper show that compliance with budget frameworks improves under temporarily stable preferences (e.g. the absence of external shocks), more homogenous preferences within the government (e.g. majoritarian governments in contrast to coalition government), preference similarity between the finance minister and the prime minister (in case of mediation), and increasing transaction costs. In other circumstances, multi-annual frameworks will not be able to block any upward pressure on expenditures.
\end{abstract}

Keywords Public spending $\cdot$ Multi-year budgets $\cdot$ Budgetary politics $\cdot$ Budget control $\cdot$ Political decision-making $\cdot$ Rules $\cdot$ Compliance

JEL Classification D73 $\cdot$ H61 $\cdot$ C72

Bernard Steunenberg

b.steunenberg@fgga.leidenuniv.nl

1 Institute of Public Administration, Leiden University, P.O. Box 13228, 2501 EE The Hague, the Netherlands 


\section{Introduction}

Multi-year budgets are broadly seen as a way to reduce the upward pressure on government expenditures during budget negotiations (Anderson and Minarik 2006). Various countries, including Sweden (Ljungman 2007), the Netherlands (Bos 2008), New Zealand, and the United States, use multi-year or multi-annual budgets or budgetary caps to control government expenditure. Separating the choice of the overall budget from the choice of budget allocations is expected to constrain subsequent distributional choices. This budgeting framework fits into a broader literature that indicates that institutions affect economic and fiscal policy outcomes (Persson et al. 1997; Persson and Tabellini 2003, 2004; Von Hagen and Harden 1995; Volkerink and De Haan 2001; Hallerberg et al. 2009; Blume and Voigt 2013; Caruso et al. 2015; Efendic et al. 2011).

Less clear is why multi-year expenditure guidance will provide a 'binding' ceiling on annual expenditures. This concern is reflected in a recent analysis by the European Commission. Based on a review of all national budgeting procedures in the EU, the Commission recommends that member states strengthen their national medium-term budgets by introducing 'more binding elements' (European Commission 2012: 6). In other research, Reuter (2015: 77) finds that for 11 EU member states in the period 1994-2012 “...that countries comply with their fiscal rules only in half of the years." Concerned about the increasing budget deficits in the euro-zone is also evident in the Fiscal Compact, which requires member states to introduce "... provisions of binding force and permanent character, preferably constitutional, or otherwise guaranteed to be fully respected and adhered to throughout the national budgetary processes" (Article 3.2). ${ }^{1}$

Compliance with expenditure rules, especially when these rules do not generate outcomes that are preferred by the main political actors, is a problem that lies at the heart of budgetary politics.

In this paper, I analyze the extent to which multi-year budgets are sensitive to renegotiation. That fact that political actors have agreed to specific budget ceilings does not necessarily imply that they will abide by or enforce these ceilings later on. For example, changes in preferences may generate pressure to change the initial agreement.

In this paper, such changes are introduced as an external shock that affects policy preferences. After a shock, ministers choose the actual budget for a ministry in view of the status quo budget based on the multi-annual framework. The interaction between the finance minister and a spending minister is modelled as a game in which the spending minister makes a proposal, which needs to be accepted by the finance minister. The base-line version of this model shows that compliance with budget ceilings only occurs when the finance minister prefers the budget ceiling to the proposal made by the spending minister. In all other circumstances, players will

\footnotetext{
1 Treaty on Stability, Coordination and Governance in the Economic and Monetary Union of 2 March 2012, which came into force on 1 January 2013. Available at https://eur-lex.europa.eu/legal-content/EN/ ALL/?uri=celex:42012A0302(01).
} 
accept a higher budget leading to noncompliance with the previously adopted budget ceiling, and, possibly, an overall budget deficit.

The base-line model is further developed by looking into three different ways of creating greater compliance with a multi-year budget. First, uncertainty about the finance minister's preferences is introduced, so that the spending minister does not know for sure what the finance minister wants. This change only impacts outcomes when the finance minister already wants more spending. Second, positive transaction costs are introduced reducing the finance minister's incentive to change. These costs result into more compliance by making the finance minister less responsive to alternative budget proposals from the spending minister. Third, the prime minister is introduced as a third player, who can mediate between the other two players, especially when a conflict about the proposed budget allocation is sufficiently 'scaled up' to be of interest to the prime minister. The impact of this arrangement depends on whether the finance minister and prime minister have similar preferences and work in tandem. If they $d o$, it helps improving compliance. If they do not, and the prime minister is for instance from a different political party, his involvement may have the unintended effect of reducing compliance.

The results show that the use of multi-annual budgetary frameworks allow for a range of different outcomes, including ones in which players deviate from a previously accepted budget and agree to spend more. Compliance to budget frameworks is conditional and depends on factors discussed in this paper. For example, the magnitude of the external shock plays a role. While a 'small' shock may not change much, a 'substantial' shock has more impact and leads to more instances of noncompliance.

To develop and present these findings, the paper is organized as follows: After discussing the literature on multi-annual budget frameworks (Sect. 2), the analysis starts with the base-line model (Sect. 3). To analyze how compliance with budget frameworks can be improved, the first step is to introduce uncertainty (Sect. 4). The next step is adding positive transaction costs showing how these costs may affect decision-making (Sect. 5). Finally, political is included through prime minister involvement (Sect. 6). Section 7 concludes the paper.

\section{Budgeting rules, politics, and budgets}

The question about compliance with multi-year or multi-annual budgets-terms which are used interchangeably in this paper-can be related to the classical problem of the endogeneity of rules to preferences. If rules are an expression of actors' preferences, then changes in preferences will also affect these rules. Riker (1980), who first noted this problem, therefore defined rules as 'relative' constants suggesting that the likelihood of changing them are lower than for preferences. This likelihood can be a function of various factors including the occurrence of specific preferences or costs.

Riker's idea has two, closely related implications for multi-annual budget frameworks, like the ones used in the context of the EU and many European countries. The first implication is that the effectiveness of budget frameworks, conceived as a 
set of expenditure rules, is conditional on the political context within which budgetary decisions are made. Frameworks will not always have the same, constant impact. The second implication is that for some preference configurations or high levels of costs, budget frameworks will be binding and can be used to constrain budgetary decision-making. However, beyond some point, the initial agreement will no longer be supported, leading to noncompliance and change. This paper shows the conditions under which compliance and noncompliance with budget frameworks will occur.

Empirical studies on the use of budget ceilings, with the balanced budget requirement as its most restrictive type, highlight this problem of compliance (see for example Von Hagen 1991; Canova and Pappa 2006; Von Hagen and Wolff 2006). In her review of these studies, Eslava (2011: 662) concludes that “...numerical targets seem to have limited effectiveness".

With regard to how the institutional context of the decision-making process may affect these results, Von Hagen (2006: 48) distinguishes between bargaining between actors on equal footing ('contract' approach) and situations in which the finance minister, on behalf of the government, needs to broker a deal with each of the individual spending ministers ('delegation' approach). In both cases, the results seem to be dependent on the relative 'power' of actors.

Concerning a 'contract' approach, Von Hagen (2006) finds that the responses of EU member states to the constraints imposed by the Stability and Growth Pact vary per country. Especially in smaller countries, spending levels as well as deficits seem to be reduced, suggesting that national compliance with these rules might be inversely related to the power of countries in the Union's main institutions.

This paper extends analysis of what may be called a 'delegation' approach to national budgets. Von Hagen and Harden (1995) develop a model analyzing the trade-offs between spending and taxation for national governments and their spending ministers. They show that a finance minister with strong powers in the budget process may reduce the impact of spending ministers bending the outcome towards a 'collectively' optimal budget. Hallerberg et al. (2009: 28-31) report a similar finding using a model in which the finance minister has strong proposal power.

However, it is not yet clear how such divisions of authority affect multi-year budgeting and subsequent possibilities for renegotiation. When budget ceilings deviate more from the preferences of the participating ministers, the pressure to change the initial agreement will increase, and spending ministers within the government may conspire to obtain a higher budget. Furthermore, when the finance minister is also a politically motivated actor-which mostly is the case-the assumption from previous work that she acts as a 'benevolent agenda setter' can also be questioned. A finance minister with substantive preferences will no longer impose a Pareto optimal 'solution' for the government as a whole but attempt to advance her own interests or that of her party instead.

In this paper I do not assume a strong finance minister who acts as behalf of 'the' government but focus on budget negotiations in which individual preferences, decision-making rights, information and the sequence of play all affect outcomes. Starting with a model in which preferences and authority both have effects, I will show how introducing uncertainty, adding costs to the finance minister's utility function 
and changing the sequence of play affect equilibriums in which budget ceilings are respected or not.

\section{Multi-year budgeting as a game}

Multi-annual budgeting frameworks separate decisions on budget ceilings from ones on the annual allocations to ministries (Kraan 2008). The budgetary process, in this context, starts with a decision on the government's overall expenditure ceiling, which is translated into ceilings per policy area or ministry. These ceilings are determined well in advance. This can be done at the start of a government's term (for instance as part of a coalition agreement, or the inaugural declaration of a new government) in case of a 'fixed' framework, or by including for each year a future fiscal year (for instance, including in each year the agreement for $t+4$ ) in case of a 'rolling' framework. By making a choice about the size of the overall government's budget well before the annual negotiations about a ministry's budget, this procedure attempts to disconnect the choice of size from a choice of mix - and so reduce what some have termed the fiscal commons problem. Subsequent annual negotiations are then 'reduced' to decisions on ministry budgets within the ceilings previously established.

The annual negotiations focus on the estimates provided by the spending minister supporting his proposed budget. Since the finance minister will initially stick to the budget ceiling as the maximum feasible estimate, the spending minister makes the 'first offer'. This estimate describes the expected financial consequences of the implementation of current policy, including new elements approved by the legislature. Shortfalls in spending, changes in the way public services will be delivered, and new policy can be reasons for proposing higher estimates.

In the aggregate of all estimates have to match be equal or less than the ceiling to keep the spending minister in compliance with the government's fiscal agreement. The finance minister monitors the spending minister's proposal and will engage in negotiations using the ceiling as the status quo budget. The choice of the status quo for multi-annual budgeting therefore differs from classical studies on budgeting (Fenno 1966; Kiewiet and McCubbins 1988) in which a constitutionally prescribed 'reversion rule' is often used (Romer and Rosenthal 1978: 30). Multi-annual budgeting can be seen as a two-step process. First, an agreement on budget ceilings is worked out, and, second, at a later date, fitting actual budgets are chosen, based on proposed budgets by spending ministers. Compliance is the extent to which the relevant government decision makers (players) maintain the agreed budget ceiling in the actual budgets.

\subsection{Players, preferences and sequence of play}

In developing this game, I start with an extended game in which players set a multiannual budget framework in the first period This framework provides budget ceilings for each spending ministry for a number of years. The ceilings serve as the 
status quo ante for subsequent rounds of decision-making. After agreement to that budgetary framework, I assume that some random external shock occurs. This shock affects government revenues and/or the relative prices of government output thus shifting the players' preferences (as reflected by their ideal positions). ${ }^{2}$ Although players may know the ideal positions of the other players in the first period, they are not aware of their utility functions. Consequently, any shock causes uncertainty about preferences and may change ideal positions. ${ }^{3}$ In the second round, players negotiate over the annual budget appropriation based on the previously accepted status quo ante budget, $q$.

The uncertainty caused by an external shock implies that the first-round agreements may no longer be acceptable to all of the ministers that had signed off on it in the first period. It also allows us to focus on the second round of the game. In this 'reduced' game players decide on the annual budget.

The players are the spending minister, $s$, and the finance minister, $f$, with ideal positions at $S$ and $F$, respectively. The sequence of play in period two (in which budgets are ultimately decided) is that in the first stage the spending minister makes a proposal and submits it to the finance minister. In the second stage the finance minister reviews the proposal and decides whether to enforce the status quo ante. The finance minister's action set is $v=\{1,0\}$, that is, accept or reject (e.g. veto) the proposal. I also assume that rejection imposes a very small cost on the spending minister.

The budgetary space will be represented with a one-dimensional outcome space $X=R{ }^{4}$ The preferences of a player $i$ are defined by a utility function $u_{i}($.$) ,$ which is single-peaked at $I$ and satisfies the single-crossing property. ${ }^{5}$ Define $i(q)$ as player $i$ 's indifference point to $q$. The preference set of the spending minister is $\mathrm{P}=\left\{x \mid u_{s}(x)>u_{s}(q)\right\}$ and for the finance minister $\mathrm{W}=\left\{x \mid u_{f}(x)>u_{f}(q)\right\}$. Define $x^{*}=\min (|S-x|)$ for $x \in \mathrm{P} \cap \mathrm{W}$ and $\mathrm{P} \cap \mathrm{W} \neq \varnothing$, which is a point with the smallest distance to $S$ from the intersection of $\mathrm{P}$ and $\mathrm{W}$.

\footnotetext{
2 Recall that single peaked preferences, as used in spatial models of political decision-making, are based on the presumption of given prices and income. See, for example, Cullis and Jones' (1992: 98-9) discussion of this connection. A change of one of these parameters will shift the ideal points to another position along the substantive policy dimension.

3 In the second round of the game the ideal position of a player $i$ is linked to the one in the first round as follows: $I_{2}=I_{1}+u_{i}(\xi)$ with $\xi$ as the external shock and $I$. as player $i$ 's ideal position. Since function $u_{i}$ is private knowledge, the ideal position $I_{2}$ will not be known to player $j \neq i$. Also note that uncertainty about the magnitude of $\xi$ is sufficient to cause uncertainty about ideal positions.

4 Although the model is specified for a one-dimensional outcome space, the main results also apply to a more dimensional space. The only difference is that in a more dimensional outcome space more instances of compromising and accommodating finance minister types exist, making a straightforward objection against a budgetary shift, as the guardian type does, less frequent. Since using a more dimensional space will make the presentation of the main argument more complex, I prefer, facing this tradeoff, the simpler presentation.

5 In other words, these functions satisfy for two players $i$ and $j$ the condition $\mathrm{d} u_{i} / \mathrm{d} x<\mathrm{d} u_{j} / \mathrm{d} x$ for $I<J$.
} 


\subsection{Comparing outcomes: a base-line model}

To compare the outcomes of the various models, I use a simple base-line model in which players do have information about their preferences. To simplify the presentation of outcomes, the spending minister is assumed to prefer spending levels equal to or higher than the agreed budget ceiling (that is, $S \geq q$ ). This preference configuration allows us to focus on compliance with the framework: if all players prefer a spending level lower than $q$, they will obviously comply with the ceiling imposed by the framework. In this game, the finance minister accepts the offer when $x \in \mathrm{W}$. Knowing this, and if the spending minister wants to deviate from $q$, he needs to select an offer from W as well as P. Depending on preferences, two equilibriums (with an optimal proposal of $s$ and a veto-reply from $f$ ) can be distinguished: $(q, 1)$ if $\mathrm{W} \cap \mathrm{P}=\varnothing$ with equilibrium outcome $q$, or $\left(x^{*}, 1\right)$ if $\mathrm{W} \cap \mathrm{P} \neq \varnothing$ with outcome $x^{*} .6$ The possible equilibriums of this game lead to an important observation:

Result 1 (Budgetary compliance) The finance minister maintains the budget ceiling $q$ when this point divides the finance and the spending ministers (i.e. $F \leq q$ ).

Result 1 has an interesting corollary. The moment the basic condition of this result is no longer satisfied, the players may decide differently:

Corollary (Probability of noncompliance) When the finance and spending ministers both prefer a higher budget, budget ceiling q may not be maintained.

Whether and to what extent players will deviate from the budget framework will be further explored in this paper.

The outcomes of the base-line game are illustrated in Fig. 1 in which the status quo ante, $q$, and the spending minister's ideal position, $S$, are fixed. The solid line represents the equilibrium outcome for different preferences of the finance minister, while the dotted line indicates the location of the status quo ante. For guarding finance ministers (that is, $F \leq q$ ) the budget ceiling is well protected as the solid line indicates. Only for more 'activist' finance ministers (that is, $F>q$ ) will both players agree to adjust the budget ceiling. Here two different kinds of finance ministers may exist. ${ }^{7}$ The first type is compromising, that is, the finance minister is willing to accept intermediate solutions that are satisfactory for the spending minister as well (or $q<F<w)$. The second type is accommodating $(F \geq w)$, which is a rather unlikely class of preferences for a finance minister (see also Matthews 1989: 351).

\footnotetext{
6 Note that, for $S \geq q, \mathrm{W \cap P}=\varnothing$ if $F \leq q \wedge S \geq q$, which is the condition of result 1. Otherwise, $\mathrm{W} \cap \mathrm{P} \neq \varnothing$, which occurs if $F, S>q$. For $F, S>q, x^{*}$ equals $S$ if $S \leq f(q)$, or $f(q)$ if $S>f(q)$. These conditions imply that optimal offers are selected from the interval $(q, f(q)]$.

7 The critical point, $w$, which turns a compromising type into an accommodating one, equals the point at which a finance minister, having a preference like this, is indifferent between the spending minister's ideal position $S$ and the status quo ante $q$. For symmetrical utility functions, $w=1 / 2(q+S)$.
} 


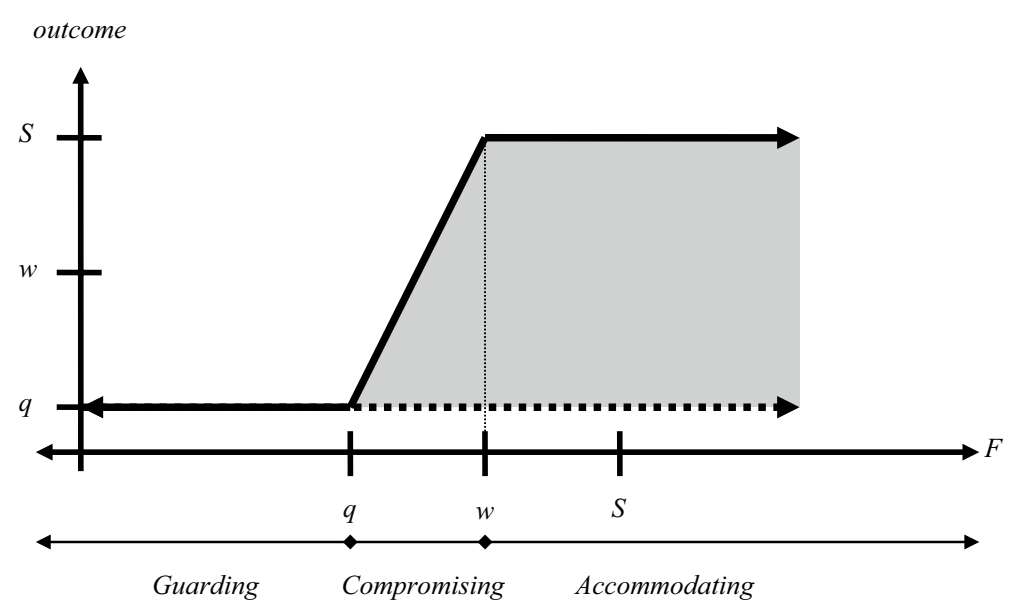

Fig. 1 The outcome of the base-line game for different preferences of the finance minister $(F)$

The accommodating finance minister no longer constrain the spending minister and is willing to provide a substantial amount of additional funds.

The outcomes for the base-line model show that for compromising and accommodating types' compliance with the multi-annual framework is reduced. These deviations, based the finance minister's higher spending preferences, are indicated by the grey surface in the figure. Comparing these surfaces between different games gives an indication of the change in compliance with the framework.

\section{The impact of uncertainty: shielding preferences}

A first step to explore whether budgetary compliance can be improved is by introducing uncertainty. If the spending minister is not sure about the finance minister's preferences, will this have an impact on compliance? To answer this question, I use a signaling model. As before, the spending minister drafts a budget proposal, that will be reviewed by the finance minister, but the question is what does the finance minister really want?

To model the spending minister's uncertainty, I first amend the utility function for finance minister $f$ to $u_{f}(., t)$, which is now dependent on her type $t$. To simplify the argument in this paper, I assume that the finance minister can be of one of two types, $t \in\{1,2\}$, which are associated with different views on how current policies within the jurisdiction of the spending ministry translate into new budget estimates. These types only differ in terms of ideal position: one type prefers a relatively 'high' value on the outcome dimension, while the other type prefers a 'low' value, that is, $F_{1}>F_{2}$. Working with two types captures the idea that a spending minister may have a broad idea about what the finance minister wants but has difficulty specifying the finance minister's preferences, especially when the finance minister favors 
Table 1 Possible combinations of finance minister types for $F_{1}>F_{2}$ and $S>q$

\begin{tabular}{llll}
\hline & $F_{1}:$ & & \\
\cline { 2 - 4 }$F_{2}:$ & Guarding $(g)$ & Compromising $(c)$ & Accommodating $(a)$ \\
\hline Guarding $(g)$ & I & II & III \\
& $\{g, g\}$ & $\{g, c\}$ & $\{g, a\}$ \\
Compromising $(c)$ & - & IV & $V$ \\
& - & $\{c, c\}$ & $\{c, a\}$ \\
Accommodating $(a)$ & - & - & VI \\
& & & $\{a, a\}$ \\
\hline
\end{tabular}

more spending. ${ }^{8}$ Both types can be based on the guardian $(g)$, compromising $(c)$ or accommodating (a) preferences distinguished before (see Fig. 1). Second, since the spending minister is not sure about the type of finance minister, beliefs, $\mu$, are added to the model. Prior to the budgetary process these beliefs of the spending minister are defined by a probability function $p$, which assigns a strictly positive probability to each of the possible types. Let $p$ denote the probability that the minister is of type 1 , so $(1-p)$ gives the probability that the minister is of type 2 ; let $\mu\left(F_{t} \mid \kappa\right)$ denotes the conditional probability that the finance minister has ideal position $F_{t}$ given the release of signal $\kappa$.

The game starts with a communication $\kappa$ by the finance minister, in which she clarifies how the budget framework will be applied. After this communication, the game will have two next stages as before in which the spending minister may adapt his beliefs and proposes an estimate, and the finance minister decides whether to accept the estimate. Focusing on equilibriums in pure strategies, an equilibrium in this game is described as an optimal combination of a communication by the finance minister $\kappa$, beliefs of the spending minister about the finance minister's type $\mu$, a proposal for a budget estimate by the spending minister $x$, and the finance minister's decision on the estimate $v$, or briefly $(\kappa, \mu, x, v)$.

Based on the three categories of finance minister types, a total of six different combinations of types may occur (see Table 1). Although for each combination one or more equilibriums in pure strategies exist, not all equilibriums are equally interesting from a strategic point of view. For some combinations, like having two guarding types (combination I), the spending minister does not need to update his beliefs, since both types favor the same action, that is, sticking to the budget ceiling (as indicated by Result 1). ${ }^{9}$ This kind of preference is often associated with a finance minister, but other, more generous preferences could be possible and should not be ruled out. The opposite occurs when both types are accommodating (combination

\footnotetext{
8 Of course, there are many more ways of modeling uncertainty and using types. The analysis in this paper shows only a limited impact on compliance. Moving to continuous types or adding features such as signaling costs to the calculus may not lead to more promising results.

9 For combination I or $\{g, g\}$ : with communication $\kappa=q, s$ can only propose $x=q$, irrespectively of $\mu$, which will not be vetoed (i.e. $v=1)$ by $f$, leading to equilibrium $(q, \mu, q, 1)$ with outcome $q$.
} 


\section{(A) Two compromising types}

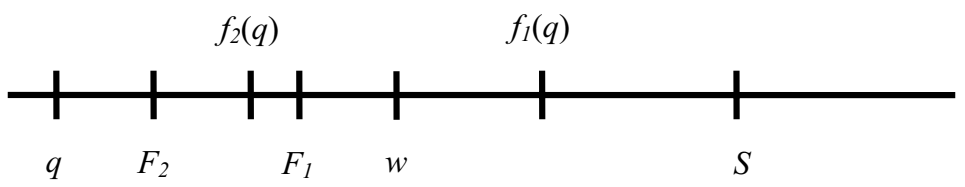

(B) Compromising and accommodating types

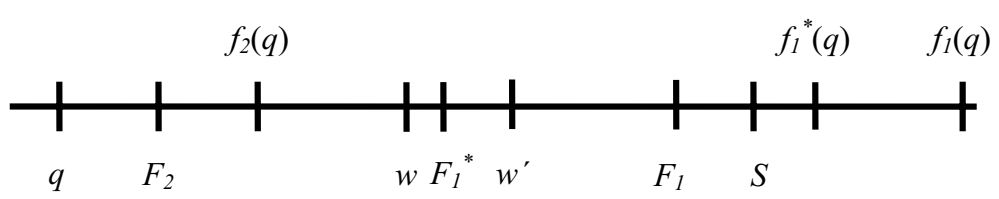

Fig. 2 Two compromising types of the finance minister

VI): having rather generous preferences, which are signaled, the finance minister does not constrain the spending minister, which successfully proposes his most preferred budget estimate. ${ }^{10}$ In other combinations, the finance minister reveals her type because hiding her preferences will lead to a less preferred outcome. So, if one of the finance minister types is guarding (as in combinations II and III in the table), it will lead to an equilibrium in which both types reveal their preference. ${ }^{11}$

Only combinations for which $F_{2}$ is compromising may provide the finance minister with the opportunity to take advantage of the lack of certainty about her type. Let's first focus on what happens when both types are compromising: in this case both types are willing to accept proposals of the spending minister up to $f_{2}(q)$ as indicated in Fig. 2a. Interestingly, since type $F_{1}$ prefers $f_{2}(q)$ to $f_{1}(q)$, there is no reason for the finance minister to reveal her true preferences. She has an incentive to strategically communicate a preference other than her true one. Consequently, the communication in the first stage does not provide any useful information about the preference of the finance minister. The spending minister is not able to distinguish both types and relies on his prior belief about what type the finance minister is. His response is mainly the result of whether the expected utility of obtaining outcome $f_{l}(q)$ or $q$ outweighs the benefits of proposing the more 'conservative' budget $f_{2}(q)$. If the spending minister wrongly guesses that the finance minister is type $F_{1}$, the proposed budget will be rejected (by the true type $F_{2}$ ), leading to outcome $q .^{12}$

\footnotetext{
10 For combination VI or $\{a, a\}$ : with communicate $\kappa=S$, $s$ will propose $S$, irrespectively of $\mu$, which will not be vetoed by $f$, leading to equilibrium $(S, \mu, S, 1)$ with outcome $S$.

11 For combination II or $\{g, c\}$ : the communication reveals the type so, $\left(q, \mu\left(F_{2} \mid q\right)=1, q, 1\right)$ with outcome $q$, or $\left(f_{l}(q), \mu\left(F_{l} l f_{l}(q)\right)=1, f_{l}(q), 1\right)$ with outcome $f_{l}(q)$; For combination III or $\{g, a\}$ : similar to $\{g, c\}$ but now $\left(q, \mu\left(F_{2} \mid q\right)=1, q, 1\right)$ with outcome $q$, or $\left(S, \mu\left(F_{l} \mid S\right)=1, S, 1\right)$ with outcome $S$.

12 For combination IV or $\{c, c\}$ : no separating equilibrium exists: note that $q<F_{2}<F_{1}<w$, so $q<F_{2}<f_{2}(q)<f_{I}(q)<S$; since $u_{f l}(q)=u_{f l}\left(f_{l}(q)\right), u_{f I}\left(f_{2}(q)\right)>u_{f l}\left(f_{l}(q)\right)$ indicating that the condition 1 cannot be satisfied. Both types communicate $\kappa=f_{2}(q)$; based on prior beliefs $\mu, s$ believes that $f$ is of type $F_{1}$ or $F_{2}$, leading to:
} 
When type $F_{2}$ is compromising but $F_{1}$ is accommodating, conditions exist under which an accommodating finance minister may reveal her true preferences, leading to a separating equilibrium. Note that the spending minister will release proposal $x=S$ when he thinks that the finance minister is a lenient, accommodating type (in case of a compromising type, the proposal will be $f_{2}(q)$ ). In deciding about whether to reveal her true preferences, the finance minister compares the possible outcomes $x=S$ and $f_{2}(q)$. Only if the finance minister $f_{l}$ (weakly) prefers the proposal of the spending minister, $x$, to the conservative estimate $f_{2}(q)$, separation will occur. Or,

$$
u_{f_{1}}(x) \geq u_{f_{1}}\left(f_{2}(q)\right)
$$

This condition is satisfied when $F_{l} \geq v .^{13}$ An example of such a configuration is illustrated in Fig. 2b, in which the accommodating finance minister $F_{1}$ is closer to $S$ than $f_{2}(q)$. In equilibrium, a finance minister of this type communicates $\kappa=S$, which makes the spending minister infer that $F_{l}=A$, setting $\mu\left(F_{l} \mid S\right)=1$. The optimal response is a budget estimate $x=S$, which will not be vetoed $(v=1)$. Alternatively, if the finance minister communicates $\kappa=f_{2}(q)$, the spending minister infers that $F_{2}=C$ and adapts his prior beliefs to $\mu\left(F_{2} \mid f_{2}(q)\right)=1$. To avoid rejection, the spending minister proposes $x=f_{2}(q)$, which is accepted.

If condition 1 is not satisfied, the finance minister does not have an incentive to reveal her true preference, forcing the spending minister to rely on his priors. This is, for instance, illustrated with an accommodating finance minister with preferences $F_{1}{ }^{*}$ in Fig. 2b. Both types will communicate a 'compromise' proposal $\kappa=f_{2}(q)$, which does not provide the spending minister any information about their type. The spending minister will use his priors to propose a budget. ${ }^{14}$

The analysis suggests that uncertainty may sometimes support the finance minister in constraining the spending minister. For compromising and accommodating types, for which separation does not apply, equilibrium outcomes will be $f_{2}(q), f_{l}(q)$ or $q$ depending on the priors of the spending minister, instead of $S$

\footnotetext{
Footnote 12 (continued)

$-\left(f_{2}(q), \mu, f_{2}(q), 1\right)$ with outcome $f_{2}(q)$ if $p \cdot u_{s}\left(f_{l}(q)\right)+(1-p) u_{s}(q)<u_{s}\left(f_{2}(q)\right)$;

- $\left(f_{2}(q), \mu, f_{l}(q), 1\right)$ with outcome $f_{l}(q)$ if $p . u_{s}\left(f_{l}(q)\right)+(1-p) u_{s}(q) \geq u_{s}\left(f_{2}(q)\right)$ and $u_{f}\left(f_{l}(q)\right) \geq u_{f}(q)$ (e.g. $F$ is indeed $\left.F_{l}\right)$; or,

$-\left(f_{2}(q), \mu, f_{l}(q), 0\right)$ with outcome $q$ if $p . u_{s}\left(f_{l}(q)\right)+(1-p) u_{s}(q) \geq u_{s}\left(f_{2}(q)\right)$ and $u_{f}\left(f_{l}(q)\right)<u_{f}(q)$ (e.g. $F$ is $\left.F_{2}\right)$.

${ }^{13} w^{\prime}$ is the point at which an actor is indifferent between $S$ and $f_{2}(q)$. For symmetrical utility functions, $w^{\prime}=1 / 2\left(f_{2}(q)+S\right)$. Based on this condition, we observe for $\{c, a\}$ and $F_{l} \geq w^{\prime}$, that there is separation: note that $q<F_{2}<w \leq F_{1}<w^{\prime}$, so $q<F_{2}<f_{2}(q)<S \leq f_{l}(q)$; and since $F_{1} \geq w^{\prime}, u_{f l}(S) \geq u_{f l}\left(f_{2}(q)\right)$. The equilibrium is:

- $\left(f_{2}(q), \mu\left(F_{2} \mid f_{2}(q)\right)=1, f_{2}(q), 1\right)$ with outcome $f_{2}(q)$, or.

$-\left(S, \mu\left(F_{l} \mid S\right)=1, S, 1\right)$ with outcome $S$.

14 For $F_{l}<w^{\prime}$, there is no separation: since $q<F_{2}<w \leq F_{l}<w^{\prime}, q<F_{2}<f_{2}(q)<S \leq f_{l}(q)$, and since $F_{1}<w^{\prime}, u_{f l}\left(f_{2}(q)\right)>u_{f l}(S)$. In that case, $s$ decides based on her priors leading to:

- $\left(f_{2}(q), \mu, f_{2}(q), 1\right)$ with outcome $f_{2}(q)$ if $p \cdot u_{s}(S)+(1-p) u_{s}(q)<u_{s}\left(f_{2}(q)\right)$;

- $\left(f_{2}(q), \mu, S, 1\right)$ with outcome $S$ if $p . u_{s}(S)+(1-p) u_{s}(q) \geq u_{s}\left(f_{2}(q)\right)$ and $u_{f}(S) \geq u_{f}(q)$ (e.g. $F$ is indeed $\left.F_{1}\right)$; or.

- $\left(f_{2}(q), \mu, S, 0\right)$ with outcome $q$ if $p \cdot u_{s}(S)+(1-p) u_{s}(q) \geq u_{s}\left(f_{2}(q)\right)$ and $u_{f}(S)<u_{f}(q)$ (e.g. $F$ is $\left.F_{2}\right)$.
} 


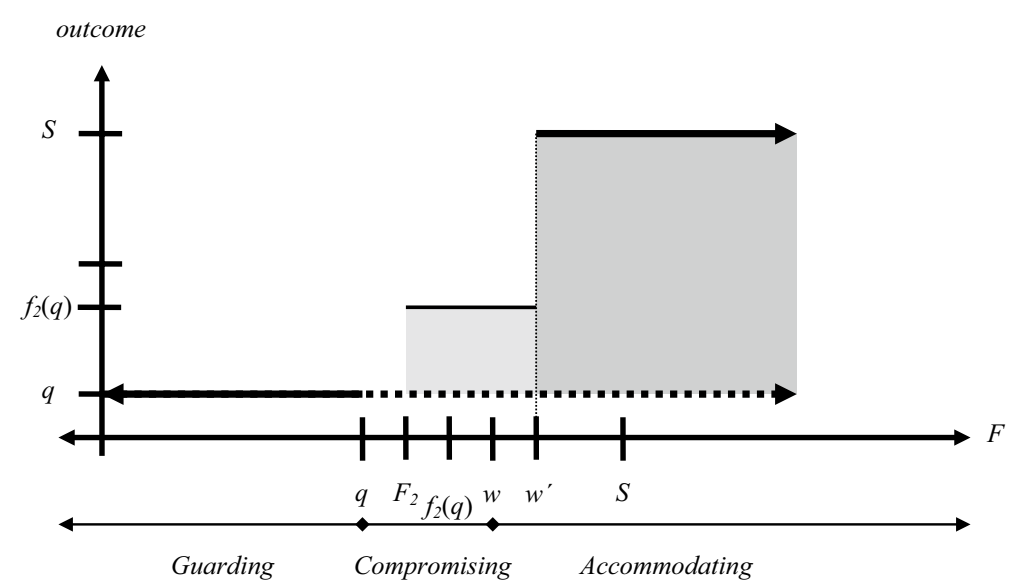

Fig. 3 Outcomes under uncertainty for different preferences of the finance minister $(F)$

(the outcome for an accommodating finance minister in Fig. 2a). Figure 3 illustrates these outcomes. In this figure the 'lower' preference of the finance minister $\left(F_{2}\right)$ is fixed, while the minister's true preferences, which are associated with the 'higher' preference $F_{1}$, vary from $F_{2}$ and up (e.g. to satisfy the condition that $\left.F_{1}>F_{2}\right)$ ). Before passing point $w^{\prime}$ the finance minister has an incentive to shield her preference, and the outcome depends on the spending minister's prior beliefs. If the spending minister's priors are such that it wants to avoid making a mistake, it will select $x=f_{2}(q)$. The deviation from the status quo is indicated in grey. For more risk-taking spending ministers, outcomes can be $f_{l}(q)$ or $q$, but these are, at best, the same as in the base-line game. From point $w^{\prime}$ on separation occurs and outcomes are equal to those of the base-line game (see Fig. 2).

The analysis indicates that guarding types of finance ministers maintain the budget framework, as in the base-line game, while most accommodating types will not enforce the initial agreement as embedded in the status quo. Uncertainty does not affect outcomes in these cases. Uncertainty may make a difference when the finance minister prefers some adaptation of the budget framework, but to a much smaller extent than the spending minister. In that case, the finance minister has an incentive to shield her true preference from the spending minister by communicating a rather 'conservative' preference, which helps in maintaining some spending discipline and limiting the deviations from the budget ceiling. This leads to the following result:

Result 2 (Information induced, weak compliance) Under uncertainty, and if the finance minister prefers a relatively small deviations from the budget ceiling (e.g. the types are compromising, or one of the types is accommodating and the condition for separation is not satisfied), the finance minister will weakly enforce the budget ceiling. 
Compared to the base-line game, uncertainty may sometimes increase compliance with a multi-annual framework. Uncertainty helps the finance minister the moment it prefers a limited adaptation of the budget ceiling while the spending minister prefers a more substantial change. The effect is limited, and also depends on how the spending minister handles uncertainty. A more risk-taking spending minister may rightly guess the finance minister's true preferences if it were type $F_{1}$, would lead to outcomes similar to that of the base-line game. However, the flipside of this behavior is that, once in a while, the spending minister misestimates preferences leading to a rejection of the proposed budget.

\section{The impact of transaction costs: reducing policy sensitivity}

A second step in our search for compliance is to introduce transaction costs that may affect the finance minister's willingness to change. Not being able to maintain a multi-annual framework may lead to a loss of reputation for the government and specifically the finance minister. The national central bank, other fiscal authorities, like the European Commission and the European Central Bank in the euro zone, and the financial markets will have less confidence in a government that appears to be unable to maintain earlier fiscal agreements. In addition, within the government, the position of the finance minister will be questioned. By following substantive policy preferences favoring some spending ministers over others, the finance minister runs the risk of losing her authority as the main political actor responsible for fiscal policy. This will weaken the position of the finance minister within the government and vis-a-vis the spending ministers. These two elements, reputation loss as well as loss of power can be perceived as costs to the finance minister.

Transaction costs will be taken as a fixed and positive cost, $\tau$, associated with changing the status quo ante. This cost affects the finance minister's utility function, which we rewrite as $u_{f}^{\prime}(x)=u_{f}(x)-\tau$ for $x \neq q$ (and $u_{f}^{\prime}(x)=u_{f}(q)$ for $\left.x=q\right)$. If the finance minister is allowed to make a move, she will only deviate from the status quo ante if the net benefit of a new proposal, $x$, is higher than this cost (e.g. $\left.u_{f}(x)-u_{f}(q)>\tau\right)$. Applied to the base-line model, the finance minister's preference set $\mathrm{W}$ can be replaced by $\mathrm{W}^{\prime}=\left\{x \mid u_{f}(x)-\tau>u_{f}(q)\right\}$, reducing the number of instances for which this set is non-empty. Taking $\Delta$ as the resulting increment of $\tau$ on the outcome dimension $X$, the finance minister will maintain the budget ceiling $q$ up to the point $F=q+\Delta$ (instead of $F=q$ in Result 1), which broadens the range of points for which players comply with the budget framework.

Applied to the signaling model with uncertainty, transaction costs affect the occurrence of the different categories of finance minister preferences and spending minister responses. First, due to positive costs, we have a new category of 'quasiguarding' ministers $g^{\prime}$ for $q<F \leq q+\Delta$. This type behaves like a guardian keeping the status quo ante. Second, costs may reduce the occurrence of a compromise type of finance minister, who has a preference $F$ when $q+\Delta<F<w$. If costs are substantial, that is, $\Delta \geq w-q$, no compromising types exist. Finally, also accommodating types (e.g. $F \geq w$ ) are affected: accommodating types will only approve the spending minister's budget if $\Delta<S-q$. If $\Delta \geq S-q$, costs are even higher than the utility 


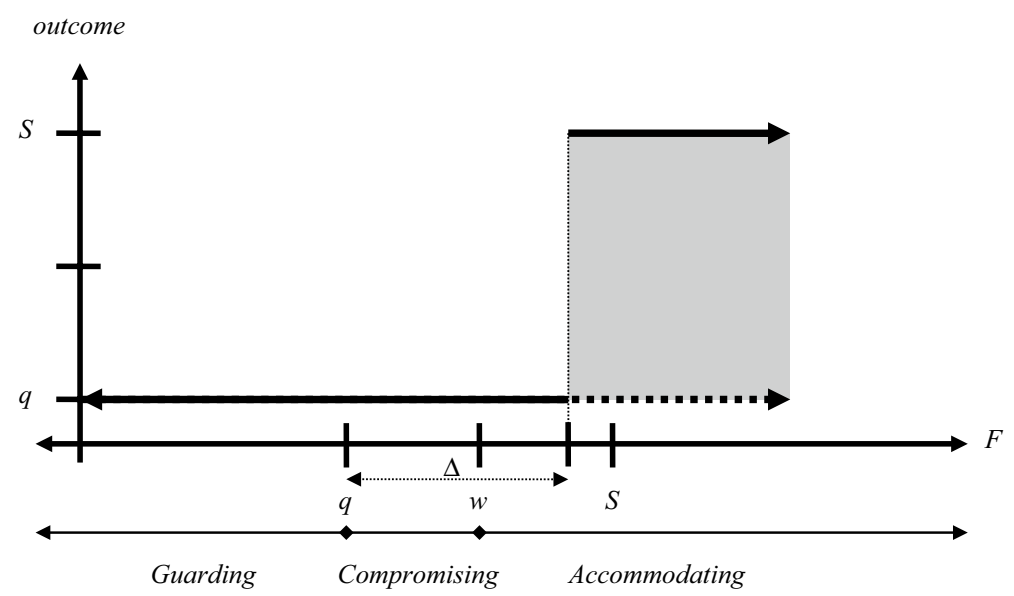

Fig. 4 Outcomes with transaction costs $(\Delta)$ for different preferences of the finance minister $(F)$

difference between the status quo and most preferred budget of the spending minister for any type of finance minister. In that case $q$ will be the only outcome.

Concerning play, a similar logic applies as in the previous section substituting the finance minister's utility function $u_{f}(x)$ with $u_{f}^{\prime}(x)$. Next to changes in the categories of ministers, this change affects the condition for separation. Furthermore, the indifference point $f(q)$ is a point $x$ for which $u_{f}(x)=u_{f}(q)+\tau$, which will be a point closer to $F$ than in the model without costs. ${ }^{15}$

Figure 4 illustrates the impact of transaction costs: depending on the size of costs $\tau$, more instances occur in which the finance minister does not have an incentive to change the status quo ante. Note that $\Delta$ is the resulting size of $\tau$ on $X$. In fact, transaction costs increase the boundary in which the finance minister will not accept a change of the status quo ante. Only 'high spending' finance ministers will support a spending minister by 'adjusting' the budget ceiling to the ministerial estimate. The grey area in Fig. 4 illustrates this, which is substantially smaller than in Figs. 1 and 3. This is based on the following result:

Result 3 (Cost induced compliance) If transaction costs are positive, also compromising and eventually accommodating types of finance ministers will maintain the budget ceiling $q$ up to the point where the utility difference between the minister's most preferred budget and the status quo is higher than these costs (e.g. $F-q>\Delta){ }^{16}$

15 The strategically most interesting combination is $\{c, a\}$. For $\{c, a\}$, separation occurs when $F_{l} \geq w^{\prime}$ and cost is small enough (if $\Delta<w-q$ ). See note 13 for equilibriums. For $F_{l}<w^{\prime}$ and costs are small enough (if $\Delta<w-q$ ), no separation occurs and the spending minister uses his priors (see note 14). For the other combinations, see Sect. 4.

16 To show this: see the definitions of types, which depend on $\Delta$. Let $F>q$ and $F-q \leq \Delta<S-q$ (if $\Delta \geq S-q$ costs are even higher than the spending minister's most preferred budget). If the spending minister proposes $x=x^{*}$, the finance minister would accept if $x * \in \mathrm{W}=\left\{x \mid u_{f}(x)>u_{f}(q)\right\}$. Since 
Of course, this positive relationship between costs and compliance also implies that the effectiveness of a multi-annual framework will be less as these costs are reduced.

\section{The impact of prime minister involvement: unintended consequences}

The last step in our analysis is to explore the impact of changing the sequence of play on compliance. We focus on the option that the bilateral negotiations require mediation and are expanded to include a third actor, namely the prime minister. In many systems with cabinet governments, the prime minister bears political responsibility for government as a whole. When the finance minister and the spending minister do not agree, the conflict can be 'scaling up' to the prime minister who makes a decision.

The sequence of play is changed such that the spending minister decides to involve the prime minister if the finance minister vetoes her proposal. In the last stage, the prime minister reviews the budget estimate $x$ in view of ceiling $q$, as indicated by the budget framework, and makes a final decision. The fact that the prime minister may overrule the finance minister changes the dynamic of the game. Knowing the prime minister's ideal position, each player assesses whether involving the prime minister leads to a better outcome than sticking to the status quo ante, q. In this way, the ideal position of the prime minister $M$ serves as the status quo post on which the spending minister and the finance minister determine their moves.

To analyze this game, let $m$ be the prime minister. If the prime minister makes a move, he chooses a budget $x=M$. Define the preference set of the finance minister as $\left.\mathrm{W}^{\prime}=\left\{x \mid u_{f}(x)>u_{f}(M)\right\}\right)$ and $\mathrm{P}^{\prime}=\left\{x \mid u_{s}(x)>u_{s}(M)\right\}$ as this set of the spending minister; both sets take the status quo post as point of departure. The new game points at two strategically different situations.

The first is one in which the prime minister splits both other players, that is, the prime minister is found between the spending and finance ministers (that is $\left.\mathrm{W}^{\prime} \cap \mathrm{P}^{\prime}=\varnothing\right)$. Figure 5 illustrates this situation when the finance minister is located to the left of the prime minister (e.g. is a guardian or compromising type). In that case, prime minister involvement is the only way for the spending minister to obtain a better outcome. The minister chooses, with the support of the prime minister, $x=M{ }^{17}$

The second situation is one in which the spending and finance ministers both prefer a change away from the prime minister (that is $\mathrm{W}^{\prime} \cap \mathrm{P}^{\prime} \neq \varnothing$ ). These are preference configurations in Fig. 5 in which the finance minister and the spending minister are located to the right of the prime minister (e.g. the finance minister is either

Footnote 16 (continued)

$\Delta \geq F-q, \tau \geq u_{f}(x)$ for $\forall x \in \mathrm{W}$. As a result, $\mathrm{W}^{\prime}=\varnothing$, so $f$ chooses $q$ (that is, $f$ behaves as quasi-guarding). However, if $F-q>\Delta, \exists x \in \mathrm{W}$ for which $\tau<u_{f}(x)$, so $\mathrm{W}^{\prime} \neq \varnothing$ and $f$ accepts $x^{*}$.

17 Equilibrium $(x=M, 1, M)$ if we impose a small cost on the spending minister when his proposal triggers a veto. Note that $\mathrm{W}^{\prime} \cap \mathrm{P}^{\prime}=\varnothing$ if $F \leq M \wedge S \geq M$, or $F \geq M \wedge S \leq M$, which equals the condition of Result 4. Otherwise, $\mathrm{W}^{\prime} \cap \mathrm{P}^{\prime} \neq \varnothing$, which occurs if $F, S<M$ or $F, S>M$. For $F, S>M, x^{*}$ equals $S$ if $S \leq f(M)$, or $f(M)$ if $S>f(M)$. These conditions imply that optimal offers are selected from the interval $(M, f(M)]$ (for $F, S<M$ the results mirror these conditions). 


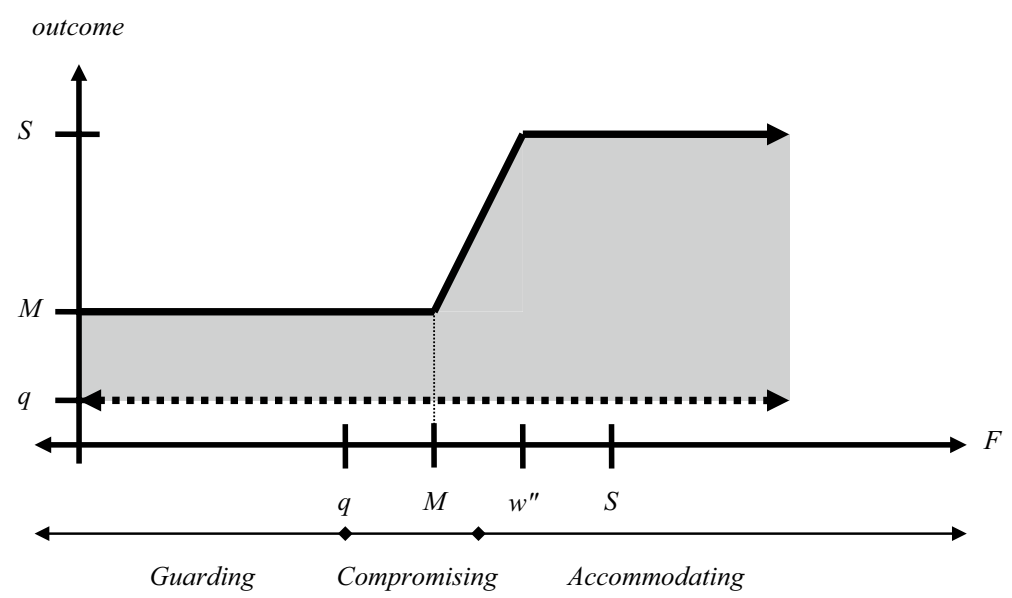

Fig. 5 Outcomes for prime minister $(M)$ mediation for different preferences of the finance minister $(F)$

compromising or accommodating). If the finance minister has preferences $F \geq w^{\prime \prime}$, the spending minister proposes $x=S$. However, if the finance minister has a preference $M<F<w^{\prime \prime}, x=f(M)$ is the best the spending minister can propose. ${ }^{18}$

These outcomes are illustrated in Fig. 5. Clearly, when the prime minister does not have preferences equal to the status quo ante (and, in this case, prefers a slightly higher budget for the spending minister), the finance minister is not able to protect the status quo. Even a guardian finance minister is forced to accept a deviation from the budget framework, if the prime minister prefers higher budget levels. This observation is expressed by our following results:

Result 4 (Prime minister intervention) When players can involve the prime minister as a mediator in the budgetary process, this player will only maintain the budget ceiling $q$ when this point equals her preference (i.e. $M=q$ ) and her preference splits the other players (i.e. $F<M<S$ or $S<M<F$ ).

The corollary of this result is:

Corollary (Prime minister driven noncompliance) When the prime minister prefers a higher budget, and the spending minister as well, the budget ceiling $q$ will not be maintained. ${ }^{19}$

\footnotetext{
18 The critical point equals the point at which the finance minister is indifferent between the spending minister's and the prime minister's ideal point. For symmetrical utility functions $w^{\prime \prime}=1 / 2(M+S)$.

19 For $M>q$ and $S>q$, equilibrium outcomes will be $M$ or $x$ (see the equilibriums of this game). To determine that $x$ cannot be $q$ : (a) if $F, S>M, x$ will be larger than $M$, and cannot, by definition, equal $q$; (b) if $F, S<M, x \in[f(M), M)$, which may include $q$ depending on $F$ (e.g. $F<q$ or $f(M)<q$ ). Since $M$,
} 
The non-compliance with the budget framework in a mediation game is illustrated with the larger grey area in Fig. 5, compared to basic game (Fig. 1) and the games with uncertainty and transaction costs (Figs. 3, 4). Political mediation has, based on our modeling, the unintended effect of making compliance with the budget framework more difficult. In addition, this game also emphasizes the importance of having rather similar preferences between the finance minister and the prime minister. The importance of this similarity is supported by recent empirical findings. Jochimsen and Thomasius (2014: 400) report that the influence of the finance minister to reduce public debt in German states is strengthened if she and the prime minister belong to the same party and have more similar preferences.

The mediation model can be extended with uncertainty so that spending minister may need to estimate the finance minister's true preferences. As discussed before, the finance minister may have an incentive not to reveal her true preferences when the minister prefers $f(M)$ to $S .{ }^{20}$ In that case, and using his prior belief, the spending minister may overestimate the finance minister's preferences leading to outcome $M$ (through a veto and an appeal). Also, the spending minister may underestimate these preferences and propose $f_{2}(M)$, which will be accepted.

\section{Applications and conclusions}

Exploring how political actors will comply with multi-annual budget frameworks, the paper provides insight into the conditions under which a finance minister is likely to support the status quo budget and comply with the agreed budget ceiling. As shown, compliance with this framework depends on the interplay between the preferences and types of key players, transaction costs, decision-making rules and uncertainty.

To summarize the results in a more concise manner, I will distinguish between two important preference profiles. The first one is majoritarian government, which consists of players with preferences that are very much alike, because they are affiliated with the same political party. In this profile, the prime minister and the finance minister have rather similar preferences, which resemble the agreement as embedded in the budget framework. Furthermore, this type can be associated with guardian or compromising preferences on the part of the finance minister as described in this paper. The second profile type is coalition government, which includes several political parties with rather different preferences. Ministerial posts are allocated to different political parties, especially the more important ones such as the position of

\footnotetext{
Footnote 19 (continued)

$S>q, s$ selects his best (closest) proposal from $[f(M), M)$, which is: (i) $x=S$ if $S>f(M)$ : since, by definition, $S>q, x$ is not equal to $q$; (ii) $x=f(M)$ if $S<f(M)$ : since $S>q$, it must be that $f(M)>q$, so $x$ cannot be $q$.

20 Due to prime minister involvement the condition of separation changes and is now: $u_{f_{1}}(x) \geq u_{f_{1}}\left(f_{2}(M)\right)$ for the two types $F_{1}>F_{2}$. However, if $u_{f_{1}}(x)<u_{f_{1}}\left(f_{2}(M)\right)$, the finance minister of type 2 prefers the proposal from type 1 and has no incentive to reveal her true preferences, and, in the same way as our model under uncertainty, different equilibriums may occur including the vetoing of the spending minister's proposal when this minister would have preferred a different outcome.
} 
prime minister and finance minister. This type can be associated with accommodating types of preferences. I will also distinguish between different kinds of external 'shocks', which affect the location of finance minister's preference vis-à-vis the status quo ante. A small shock means that the finance minister still prefers to maintain the status quo (e.g. $F<q)$; in a case of a substantial shock this minister prefers budget levels beyond the status quo $(F>q)$.

The results of the analysis are summarized in Table 2. Departing from the baseline model, the model with uncertainty introduces a spending minister who does not know the preferences of the finance minister. The transaction costs model experiments with different levels of costs, which have a dampening effect on the behavior of the finance minister. The political mediation model introduces the prime minister as a third player in the budgetary process, which changes the focus from the status quo ante to the prime minister's ideal position as the status quo post. In case of a small shock, the finance minister is able to protect status quo ante against the demands of the spending minister in most models (see Table 2a). The framework helps as a tool to constrain public expenditure and to avoid higher spending. An exception occurs for the political mediation model in the context of coalition governments: since, in this case, the prime minister is assumed to have difference preferences than the finance minister, the outcome of the decision-making process is found to be equal to the prime-minister's preference. This adverse effect on compliance is the result of scaling up a conflict to the prime minister, which changes the point of departure of the game from the status quo ante to a new status quo post.

In case of a substantial shock, after which players prefer a higher spending level than before, the results suggest that compliance with multi-annual frameworks will be less (see Table $2 b$ ). The only model that may reduce the incentive to set a higher budget is the transaction costs model. If these costs are high enough to the finance minister to offset the benefits of increasing the budget, this player will continue to maintain the status quo ante. The models with uncertainty as well as political mediation mostly produce outcomes that are associated with higher budget levels, indicating that under these conditions budget frameworks are not able to constrain spending. Another interesting effect is that majoritarian governments, if there is a need to

Table 2 Compliance with multi-annual budget frameworks under different arrangements

\begin{tabular}{|c|c|c|c|c|c|c|c|c|}
\hline & \multicolumn{2}{|c|}{ Base-line model } & \multicolumn{2}{|c|}{ Model with uncertainty } & \multicolumn{2}{|c|}{$\begin{array}{c}\text { Model with transaction } \\
\text { costs }\end{array}$} & \multicolumn{2}{|c|}{$\begin{array}{c}\text { Model with political } \\
\text { mediation }\end{array}$} \\
\hline $\begin{array}{r}\text { Type of } \\
\text { government }\end{array}$ & outcome & impact & outcome & impact & outcome & impact & outcome & impact \\
\hline \multicolumn{9}{|c|}{ 2a. After a small external shock (e.g. $F<q)$} \\
\hline -Majoritarian & $q$ & compliance & $q$ & compliance & $q$ & compliance & $q$ & compliance \\
\hline -Coalition & $q$ & compliance & $q$ & compliance & $q$ & compliance & $M$ & $\begin{array}{c}\text { non- } \\
\text { compliance }\end{array}$ \\
\hline \multicolumn{9}{|c|}{ 2b. After a substantial external shock (e.g. $F>q)$} \\
\hline -Majoritarian & $f(q)$ & $\begin{array}{c}\text { non- } \\
\text { compliance }\end{array}$ & $\begin{array}{c}q \text { or } \\
f_{2}(q)\end{array}$ & $\begin{array}{c}\text { (non-) } \\
\text { compliance }\end{array}$ & $q$ & compliance & $\begin{array}{c}f(M) \text { or } \\
M\end{array}$ & $\begin{array}{c}\text { non- } \\
\text { compliance }\end{array}$ \\
\hline -Coalition & $S$ & $\begin{array}{c}\text { non- } \\
\text { compliance }\end{array}$ & $\begin{array}{c}f_{2}(q) \text { or } \\
S\end{array}$ & $\begin{array}{c}\text { non- } \\
\text { compliance }\end{array}$ & $\begin{array}{c}\text { q or } \\
S\end{array}$ & $\begin{array}{c}\text { (non-) } \\
\text { compliance }\end{array}$ & $\begin{array}{c}f(M) \text { or } \\
S\end{array}$ & $\begin{array}{c}\text { non- } \\
\text { compliance }\end{array}$ \\
\hline
\end{tabular}

Key: $q=$ status quo ante; $F=$ the ideal position of the finance minister; $M=$ ideal position prime minister; $S=$ ideal position spending minister; $f(q)=$ indifference point to $q$ of the finance minister; $f(M)=$ indifference point to $M$ of the finance minister; $f_{2}(q)=$ indifference point to $q$ of a type 2 finance minister. In addition, note that, $q<f_{2}(q) \leq f(q)<S$, and $q<M<f(M)$ in case of a substantial shock (Table $2 \mathrm{~b}$ ) or for a coalition government (Table $2 \mathrm{a}$ and $2 \mathrm{~b}$ ) 
change the status quo ante, mostly will do better in limiting overspending. This is a result of the more homogenous preferences of these governments.

The findings illustrate that multi-year or multi-annual budget frameworks only have a conditional effect on government spending based on the explored relationships between preferences, costs, rules and uncertainty. Their effectiveness depends on the size of external shocks, but also on the political context. In relatively stable economic circumstances, governments are able to comply with budget frameworks, even if there is some preference heterogeneity within the government. Under more fragile economic conditions, compliance mainly depends on preferences and costs. Only strong preference homogeneity that supports the status quo budget or high transaction costs tend to yield budgets that comply with a previously adopted budget ceiling. In all other cases, the initial agreement as embedded in the budget framework will no longer be supported, leading to noncompliance and increases in expenditures.

The endogeneity of budgetary rules implies that they cannot be 'absolute' constraints on future budgetary negotiations. Budgetary ceilings are elastic, and the extent to which a ceiling may be stretched is the result of its interplay with the other behavioral factors (e.g. preferences, costs and uncertainty). Given this, studies that focus on the structural or procedural features of political systems (Ardanaz and Scartascini 2014; Caruso et al. 2015; Persson and Tabellini 2003) or that simply focus on explore the determinants of finance minister's preferences (Jochimsen and Thomasius 2014; Chatagny 2015; Moessinger 2014) are ignoring important interdependencies between fiscal institutions and preferences.

Our analysis suggests connecting rules and preferences sheds better light on the political character of budgetary decision-making. Although, increasing transaction costs can limit political enthusiasm for renegotiating earlier agreements and thus help preserve the ceilings set by a budget framework, they are not always sufficient to buttress earlier budgetary agreements. Such costs may be increased if they are given greater prominence and visibility through the media, so that voters and interest groups are more aware of existing expenditure rules. Similarly, given such agreements greater attention may help to increase the costs of breaking earlier commitments (Brennan and Buchanan 1980: 202-3).

Budgetary decision-making remains inherently political. For that reason, effective constraints to budgetary processes have to be political as well.

Open Access This article is licensed under a Creative Commons Attribution 4.0 International License, which permits use, sharing, adaptation, distribution and reproduction in any medium or format, as long as you give appropriate credit to the original author(s) and the source, provide a link to the Creative Commons licence, and indicate if changes were made. The images or other third party material in this article are included in the article's Creative Commons licence, unless indicated otherwise in a credit line to the material. If material is not included in the article's Creative Commons licence and your intended use is not permitted by statutory regulation or exceeds the permitted use, you will need to obtain permission directly from the copyright holder. To view a copy of this licence, visit http://creativecommons.org/licen ses/by/4.0/. 


\section{References}

Anderson, B., \& Minarik, J. J. (2006). Design choices for fiscal policy rules. OECD Journal on Budgeting, 5(4), 159-208.

Ardanaz, M., \& Scartascini, C. (2014). The economic effects of constitutions: Do budget institutions make forms of government more alike? Constitutional Political Economy, 25, 301-329.

Blume, L., \& Voigt, S. (2013). The economic effects of constitutional budget institutions. European Journal of Political Economy, 29, 236-251.

Bos, F. (2008). The Dutch fiscal framework: History, current practice and the role of the Central Planning Bureau. OECD Journal on Budgeting, 8(1), 1-42.

Brennan, G., \& Buchanan, J. M. (1980). The power to tax: Analytical foundations of a fiscal constitution. Cambridge: CUP.

Canova, F., \& Pappa, E. (2006). The elusive costs and the immaterial gains of fiscal constraints. Journal of Public Economics, 90, 1391-414.

Caruso, G., Scartascini, C., \& Tommasi, M. (2015). Are we all playing the same game? The economic effects of constitutions on the degree of institutionalization. European Journal of Political Economy, 38, 212-228.

Chatagny, F. (2015). Incentive effects if fiscal rules on the finance minister's behavior: Evidence from revenue projections in Swiss Cantons. European Journal of Political Economy, 39, 182-200.

Cullis, J., \& Jones, P. (1992). Public finance and public choice: Analytical perspectives. London: McGraw-Hill.

Efendic, A., Pugh, G., \& Adnett, N. (2011). Institutions and economic performance: A meta-regression analysis. European Journal of Political Economy, 27, 586-599.

Eslava, M. (2011). The political economy of fiscal deficits: A survey. Journal of Economic Surveys, 25, 645-673.

European Commission. (2012). Fiscal frameworks across Member States: Commission services' country fiches from the 2011 EPC peer review, European Economy Occasional Papers nr. 91.

Fenno, R. F. (1966). The power of the purse: Appropriations politics in Congress. Boston: Little\&Brown.

Hallerberg, M., Strauch, R., \& Von Hagen, J. (2009) Fiscal governance in Europe. Cambridge: Cambridge University Press.

Jochimsen, B., \& Thomasius, S. (2014). The prefect finance minister: Whom to appoint as finance minister to balance the budget. European Journal of Political Economy, 34, 390-408.

Kiewiet, D. R., \& McCubbins, M. D. (1988). Presidential influence on congressional appropriations decisions. American Journal of Political Science, 32, 713-736.

Kraan, D. J. (2008). Programme budgeting in OECD countries. OECD Journal on Budgeting, 7(4), 1-41.

Ljungman, G. (2007). The medium-term fiscal framework in Sweden. OECD Journal on Budgeting, 6(3), $1-17$.

Matthews, S. A. (1989). Veto threats: Rhetoric in a bargaining game. Quarterly Journal of Economics, 104, 347-369.

Moessinger, M.-D. (2014). Do the personal characteristics of finance ministers affect public debt? Public Choice, 161, 183-204.

Persson, T., Roland, G., \& Tabellini, G. (1997). Separation of powers and political accountability. Quarterly Journal of Economics, 112, 1163-1202.

Persson, T., \& Tabellini, G. (2003). The economic effects of constitutions. Cambridge: MIT Press.

Persson, T., \& Tabellini, G. (2004). Constitutional rules and fiscal policy outcomes. American Economic Review, 94, 25-45.

Reuter, W. H. (2015). National numerical fiscal rules: Not complied with, but still effective? European Journal of Political Economy, 39, 67-81.

Riker, W. H. (1980). Implications from the disequilibrium of majority rule for the study of institutions. American Political Science Review, 74, 432-447.

Romer, T., \& Rosenthal, H. (1978). Political resource allocation, controlled agendas, and the status quo. Public Choice, 33, 27-43.

Volkerink, B., \& De Haan, J. (2001). Fragmented government effects on fiscal policy: New evidence. Public Choice, 109, 221-224.

Von Hagen, J. (1991). A note on the empirical effectiveness of formal fiscal restraints. Journal of Public Economics, 44, 199-210. 
Von Hagen, J. (2006). Fiscal rules and fiscal performance in the European Union and Japan. Monetary and Economic Studies (Institute for Monetary and Economic Studies. Bank of Japan), 24, 25-33.

Von Hagen, J., \& Harden, I. J. (1995). Budget processes and commitment to fiscal discipline. European Economic Review, 39, 771-779.

Von Hagen, J., \& Wolff, G. B. (2006). What do deficits tell us about debt? Empirical evidence on creative accounting with fiscal rules in the EU. Journal of Banking and Finance, 30, 3259-3279.

Publisher's Note Springer Nature remains neutral with regard to jurisdictional claims in published maps and institutional affiliations. 